\title{
Chloroplast-mediated activation of plant immune signalling in Arabidopsis
}

\author{
Hironari Nomura ${ }^{1,2}$, Teiko Komori ${ }^{1}$, Shuhei Uemura ${ }^{1}$, Yui Kanda', Koji Shimotani ${ }^{1}$, Kana Nakai ${ }^{1}$, Takuya Furuichi ${ }^{3}$, \\ Kohsuke Takebayashi ${ }^{4}$, Takanori Sugimoto ${ }^{4}$, Satoshi Sano ${ }^{1}$, I Nengah Suwastika ${ }^{1}$, Eiichiro Fukusaki ${ }^{4}$, \\ Hirofumi Yoshioka ${ }^{2,5}$, Yoichi Nakahira ${ }^{1} \&$ Takashi Shiina ${ }^{1}$
}

Chloroplasts have a critical role in plant immunity as a site for the production for salicylic acid and jasmonic acid, important mediators of plant immunity. However, the molecular link between chloroplasts and the cytoplasmic-nuclear immune system remains largely unknown. Here we show that pathogen-associated molecular pattern (PAMP) signals are quickly relayed to chloroplasts and evoke specific $\mathrm{Ca}^{2+}$ signatures in the stroma. We further demonstrate that a chloroplast-localized protein, named calcium-sensing receptor (CAS), is involved in stromal $\mathrm{Ca}^{2+}$ transients and responsible for both PAMP-induced basal resistance and $R$ gene-mediated hypersensitive cell death. CAS acts upstream of salicylic acid accumulation. Transcriptome analysis demonstrates that CAS is involved in PAMP-induced expression of defence genes and suppression of chloroplast gene expression possibly through ${ }^{1} \mathrm{O}_{2}$-mediated retrograde signalling, allowing chloroplast-mediated transcriptional reprogramming during plant immune responses. The present study reveals a previously unknown chloroplast-mediated signalling pathway linking chloroplasts to cytoplasmic-nuclear immune responses.

\footnotetext{
${ }^{1}$ Graduate School of Life and Environmental Sciences, Kyoto Prefectural University, Sakyo-ku, Kyoto 606-8522, Japan. ${ }^{2}$ Graduate School of Bioagricultural Sciences, Nagoya University, Chikusa-ku, Nagoya 464-8601, Japan. ${ }^{3}$ EcoTopia Science Institute, Nagoya University, Chikusa-ku, Nagoya 464-8603, Japan. ${ }^{4}$ Graduate School of Engineering, Osaka University, Suita, Osaka 565-0871, Japan. ${ }^{5}$ The Venture Business Laboratory, Ehime University, Bunkyo-cho, Matsuyama 790-8577, Japan. Correspondence and requests for materials should be addressed to T.S. (email: shiina@kpu.ac.jp).
} 
$\mathrm{P}$ lants are continuously exposed to a variety of biotic and abiotic stresses, and have evolved an intricate network of signal transduction pathways leading to transcriptome and metabolic reprogramming. Pathogen-associated molecular patterns (PAMPs) are recognized by pattern-recognition receptors in the plasma membrane and activate an array of basal defence responses (PAMP-triggered immunity, PTI), whereas pathogen-derived effector proteins trigger hypersensitive response (HR) cell death at the site of pathogen infection and confine the spread of pathogens (effector-triggered immunity, ETI) ${ }^{1}$. Plant immunity activates two parallel signal transduction pathways: cytoplasmic mitogenactivated protein kinase (MAPK) and $\mathrm{Ca}^{2+}$ signalling pathways leading to transcriptional reprogramming, and a chloroplastmediated pathway leading to the generation of chloroplast-derived reactive oxygen species (ROS) and the production of defencerelated hormones, such as salicylic acid (SA) and jasmonic acid $(\mathrm{JA})^{2}$. Possible involvement of chloroplasts in plant innate immunity has been discussed ${ }^{3}$. However, the molecular link between the chloroplast and cytoplasmic-nuclear immune signalling pathways remains largely unknown. In particular, it is not clear how immune signals are relayed to chloroplasts and how chloroplasts control the expression of nuclear-encoded defence genes.

Extracellular stimuli evoke $\mathrm{Ca}^{2+}$ signals in not only the cytoplasm, but also organelles such as mitochondria, peroxisomes and nuclei ${ }^{4,5}$. For example, the massive accumulation of $\mathrm{Ca}^{2+}$ in mitochondria leads to the dysfunction of mitochondria and induction of apoptosis of mammalian cells ${ }^{6}$. However, very few studies have focused on $\mathrm{Ca}^{2+}$ signals in chloroplasts. Calcium-sensing receptor $(\mathrm{CAS})^{7}$ is a thylakoid membrane-associated $\mathrm{Ca}^{2+}$-binding protein involved in the regulation of cytoplasmic $\mathrm{Ca}^{2+}$ oscillations and extracellular $\mathrm{Ca}^{2+}$-induced stomatal closure ${ }^{8-10}$.

Here we show that PAMP signals evoke a CAS-dependent transient $\mathrm{Ca}^{2+}$ signal in chloroplasts, and that CAS is involved in transcriptional reprogramming through ${ }^{1} \mathrm{O}_{2}$-mediated retrograde signalling during plant innate immunity. This study is an important advancement in the understanding of cross talk between chloroplasts and the plant immune system.

\section{Results}

Biotic and abiotic stress-induced chloroplast $\mathrm{Ca}^{2+}$ signals. To measure the free $\mathrm{Ca}^{2+}$ concentration in the stroma, the calciumsensitive bioluminescent protein aequorin was targeted to the chloroplast stroma using an ribulose-1,5-bisphosphate carboxylase (RBCS) signal peptide (Supplementary Fig. S1). As reported previously, stromal $\mathrm{Ca}^{2+}$ was maintained at a very low concentration, as low as that in the cytoplasm (Fig. 1a-f), suggesting that $\mathrm{Ca}^{2+}$ in chloroplasts is sequestered in the thylakoid lumen or by $\mathrm{Ca}^{2+}$. binding proteins ${ }^{11}$. We found that the bacterial PAMP flagellin peptide (flg22) induces a rapid $\mathrm{Ca}^{2+}$ transient in the cytoplasm, followed by a long-lasting increase in the stromal free $\mathrm{Ca}^{2+}$ level (Fig. 1a). A similar stromal $\mathrm{Ca}^{2+}$ transient was also induced by the fungal PAMP chitin (Fig. 1b). On the other hand, control peptides a

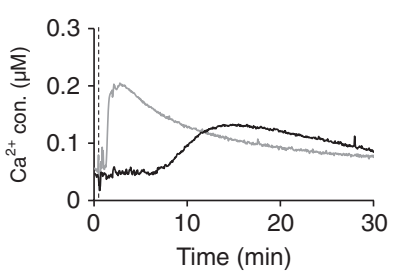

e

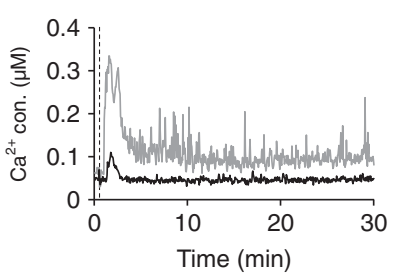

h

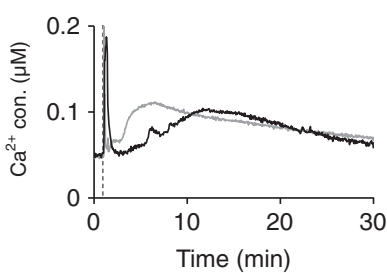

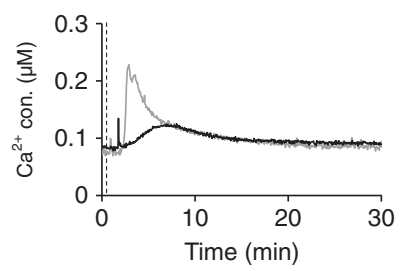

f

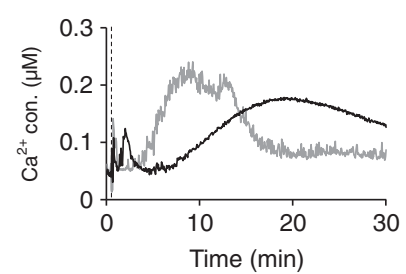

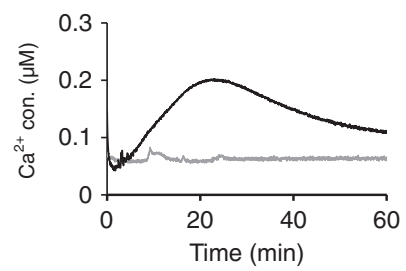

d

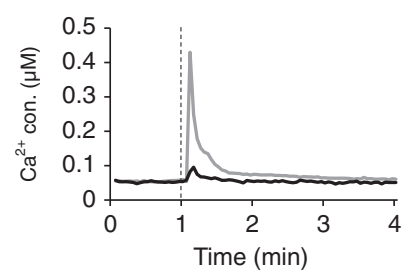

g

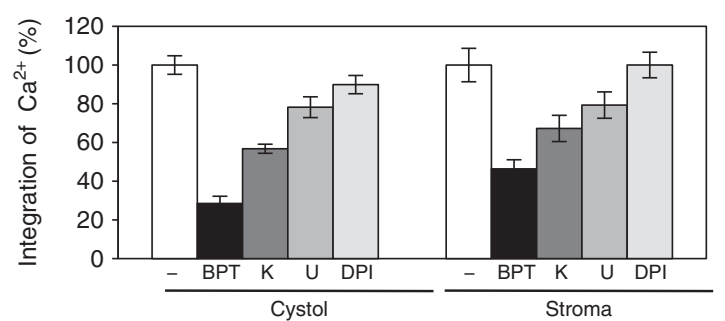

i

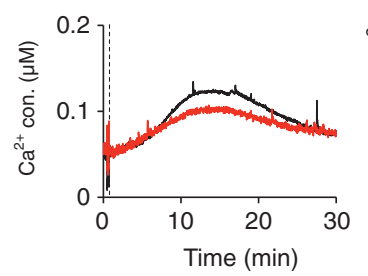

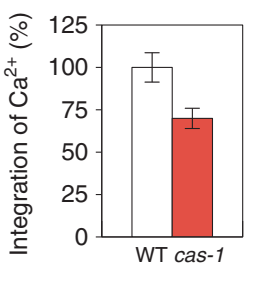

j

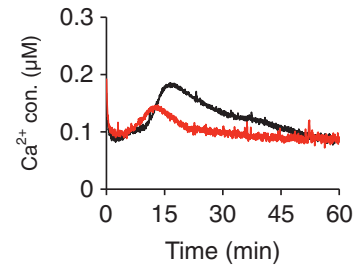

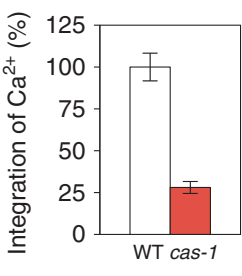

Figure 1 | Chloroplast $\mathbf{C a}^{\mathbf{2}+}$ dynamics. (a-f,h) Aequorin (AEQ) luminescence from wild-type (WT) AEQ-expressing plants treated with (a) $1 \mu \mathrm{M}$ flg22, (b) $100 \mu \mathrm{g} \mathrm{ml}^{-1}$ chitin, (c) light-to-dark transition, (d) ice-cold MS medium, (e) $200 \mathrm{mM} \mathrm{NaCl}$, (f) $500 \mathrm{mM}$ sorbitol or (h) $30 \mu \mathrm{M}$ ionomycin. The vertical dashed line indicates the time at which treatment was initiated. Experiments were repeated at least five times, with control treatments. Representative data are shown. Cytosolic and stromal $\mathrm{Ca}^{2+}$ changes are indicated by grey and black lines, respectively. (g) Effects of signal transduction inhibitors on flg22-induced cytosolic and stromal $\mathrm{Ca}^{2+}$ increase in WT AEQ-expressing plants. ' -': no inhibitor, BPT: 5 mM 1,2-bis(2-aminophenoxy)ethane N,N,N', $N^{\prime}$ tetraacetic acid (BAPTA), K: $2 \mu \mathrm{M} \mathrm{K252a}, \mathrm{U}: 20 \mu \mathrm{M}$ U-0126, DPI: $50 \mu \mathrm{M}$ DPI. The time-integrated cytosolic or stromal Ca ${ }^{2+}$ concentration upon 30-min treatment with $1 \mu \mathrm{M}$ flg22 is shown. Data are the means \pm s.e.m. of relative values $(n=4$, control values were set of $100 \%)$. (i,j) Stromal Ca ${ }^{2+}$ changes in WT (black lines, white bars) and cas-1 knockout (red lines and bars) plants expressing AEQ. Plants were treated with (i) $1 \mu \mathrm{M}$ flg22 or (j) light-to-dark transition. The integrated stromal $\mathrm{Ca}^{2+}$ concentration was reduced in cas -1 compared with WT. Data are the means \pm s.e.m. of relative values $(n=4)$. 
induced no $\mathrm{Ca}^{2+}$ signal in chloroplasts (Supplementary Fig. S2a). Furthermore, a flg22-induced stromal $\mathrm{Ca}^{2+}$ transient was observed in transplastomic tobacco plants in which the aequorin gene had been integrated into the chloroplast genome (Supplementary Fig. $\mathrm{S} 2 \mathrm{~b}$ ), confirming the occurrence of $\mathrm{Ca}^{2+}$ dynamics in the chloroplast stroma. These findings demonstrate that extracellular PAMP signals are relayed rapidly to chloroplasts and evoke intrachloroplastic $\mathrm{Ca}^{2+}$ transients.

We further examined the effects of abiotic stresses on cytoplasmic and stromal $\mathrm{Ca}^{2+}$ signals. Light-to-dark transition evoked a slow $\mathrm{Ca}^{2+}$ transient in the stroma, but not the cytoplasm (Fig. 1c) ${ }^{11}$. We also found that other abiotic stresses induced stromal $\mathrm{Ca}^{2+}$ transients in a stress-dependent manner. Cold and salt stresses elicited rapid stromal $\mathrm{Ca}^{2+}$ spikes within a minute, whereas hyperosmotic stress induced a biphasic long-lasting $\mathrm{Ca}^{2+}$ transient in the stroma (Fig. 1d-f). Stress-specific $\mathrm{Ca}^{2+}$ signatures in the stroma may be involved in the regulation of photosynthesis and metabolic processes in response to the given stresses.

In mammals, signal molecules such as staurosporine initially stimulate an increase in the cytoplasmic $\mathrm{Ca}^{2+}$ concentration, and subsequently induce a mitochondrial $\mathrm{Ca}^{2+}$ increase before apoptosis ${ }^{6}$. Similarly, PAMP-induced stromal $\mathrm{Ca}^{2+}$ transients were always preceded by cytoplasmic $\mathrm{Ca}^{2+}$ changes. We found that both chloroplastic and cytoplasmic $\mathrm{Ca}^{2+}$ changes were markedly decreased by the extracellular $\mathrm{Ca}^{2+}$ chelator 1,2-bis(2-aminophenoxy)ethane $N, N, N^{\prime}, N^{\prime}$ tetraacetic acid (BAPTA; Fig. 1g). Furthermore, the $\mathrm{Ca}^{2+}$ ionophore ionomycin induced a biphasic $\mathrm{Ca}^{2+}$ increase in both the cytoplasm and the stroma (Fig. 1h). Interestingly, the second ionomycin-induced stromal $\mathrm{Ca}^{2+}$ increase was preceded by the cytoplasmic $\mathrm{Ca}^{2+}$ transient. From these results, we presume that PAMPs first induce $\mathrm{Ca}^{2+}$ entry into the cytoplasm and, subsequently, the cytoplasmic $\mathrm{Ca}^{2+}$ triggers a transient increase in the stromal $\mathrm{Ca}^{2+}$ concentration. In addition, both the cytoplasmic and stromal $\mathrm{Ca}^{2+}$ oscillations were partially reduced by inhibitors of serine/threonine protein kinase (K252a) and MAPKKs (U-0126), but not by an NADPH oxidase inhibitor (DPI; Fig. 1g), suggesting the possible involvement of a MAP kinase cascade in the generation of cytoplasmic and stromal $\mathrm{Ca}^{2+}$ signals.

CAS is involved in chloroplast $\mathrm{Ca}^{2+}$ signals. CAS is a plant-specific thylakoid-associated $\mathrm{Ca}^{2+}$-binding protein ${ }^{8-10,12}$. To examine the possible role of CAS in the generation of stromal $\mathrm{Ca}^{2+}$ transients, we measured flg22-induced stromal $\mathrm{Ca}^{2+}$ transients in aequorinexpressing plants with a CAS knockout background (cas-1). The aequorin-expressing cas-1 plants accumulated the same amount of aequorin protein as wild-type plants (Supplementary Fig. S1a). We found that flg22- and dark-induced long-lasting stromal $\mathrm{Ca}^{2+}$ transients were markedly reduced in cas-1 (Fig. 1i,j), whereas cold-induced rapid stromal $\mathrm{Ca}^{2+}$ spikes were not impaired in cas-1 (Supplementary Fig. S3). Considering the localization of CAS in thylakoid membranes, CAS may be involved in $\mathrm{Ca}^{2+}$ release from thylakoid membranes and the generation of a long-lasting stromal $\mathrm{Ca}^{2+}$ signal.

CAS is responsible for both PTI and ETI. The presence of PAMPinduced $\mathrm{Ca}^{2+}$ transients in the stroma underscores the importance of chloroplasts in plant immune signalling. We found that cas-1 plants exhibited severely impaired resistance to the virulent bacterium Pseudomonas syringae pv. tomato (Pst) strain DC3000 and to avirulent $P s t$ DC3000 varieties (Fig. 2a). Surprisingly, PAMP (flg22)induced defence-related events, such as stomatal closure (Fig. 2b), callose deposition (Fig. 2c) and accumulation of defence-related phenylpropanoids/flavonoids and their precursors (Supplementary Fig. S4), were markedly compromised in cas-1. Furthermore, flg22induced $P R 1$ and $P R 2$ expression and stomatal closure were suppressed in two independent homozygous T-DNA insertion lines, cas-1 and cas-2 (ref. 8), whereas expression of CAS cDNA at wildtype levels in cas-1 restored flg22-induced PR1 and PR2 expression and stomatal closure (Fig. 2d, Supplementary Fig. S5). These results demonstrate that the chloroplast protein CAS is involved in a range of basal defence responses. We further found that flg22-induced stomatal closure was impaired by the NADPH oxidase inhibitor diphenyleneiodonium (DPI) and by the nitric oxide (NO) scavenger 2-(4-carboxyphenyl)-4,4,5,5-tetramethylimidazoline-1-oxyl3-oxide (cPTIO) in wild-type plants (Fig. 2e). On the other hand, exogenous application of hydrogen peroxide $\left(\mathrm{H}_{2} \mathrm{O}_{2}\right)$ or the $\mathrm{NO}$ donor sodium nitroprusside (SNP) could induce stomatal closure in cas-1 (Fig. 2f), suggesting that CAS acts upstream of ROS and NO signals in flg22-induced stomatal closure.

Some pathogens secret effector proteins (Avr gene products) that suppress PTI. Conversely, effectors are recognized by plant proteins, which activate ETI leading to hypersensitive cell death at the infection site. We found that the cas-1 plants exhibited delayed and suppressed HR cell death compared with the wild type after inoculation with Pst DC3000 (avrRpt2; Fig. 3a,b). Interestingly, the Pst DC3000 (avrRpt2)-induced accumulation of ROS (Supplementary Fig. S6a,b) and NO (Supplementary Fig. S6c,d) was significantly reduced in cas-1 plants. Functional proof that CAS is a critical component in plant cell death was further demonstrated using virusinduced gene silencing (VIGS) in Nicotiana benthamiana plants. We cloned $\mathrm{NbCAS}$ from N. benthamiana (Supplementary Fig. S7a) and used VIGS to reduce its expression to $<1 \%$ of the wild-type level (Supplementary Fig. S7b). NbCAS silencing resulted in a clear delay in the elicitor protein INF1-, the cf9/Avr9 elicitor/receptor- and the constitutively active $N$. tabacum MAP kinase kinase (NtMEK $2^{\mathrm{DD}}$ )dependent cell death (Fig. 3c,d, Supplementary Fig. S7c), suggesting that CAS has a conserved role in plant cell death and may act downstream of the MAP kinase cascade in ETI. Considering a chloroplast localization of CAS, the above results suggest that chloroplasts might have critical roles in the positive regulation of plant immunity.

CAS regulates SA biosynthesis. It is unlikely that the compromised immunity of CAS knockout plants is caused by limited cellular resources, as cas-1 plants are photosynthetically competent ${ }^{8}$ and do not show severe growth retardation (Supplementary Fig. S8). Chloroplasts are involved in the biosynthesis of plant hormones such as SA, JA, abscisic acid (ABA), indole-3-acetic acid (IAA) and cytokinins (CKs). Thus, we examined the profiles of a set of plant hormones (SA, JA, ABA, IAA and CKs) during flg22-induced PTI. The accumulation of free SA was transiently induced by flg22 treatment within $6 \mathrm{~h}$ in wild-type plants, whereas JA and other hormones showed no significant change in levels (Fig. 4a-e), confirming a crucial role of SA in PTI signalling. Importantly, we found that CAS deficiency prevented flg22-induced accumulation of free SA (Fig. 4a) as well as glycosylated SA (Supplementary Fig. S9). As the basal SA levels before flg22 treatment were normal in cas-1 plants, CAS is likely involved in the regulation of SA biosynthesis rather than the biosynthesis itself. SA is synthesized in chloroplasts via the chorismate pathway in Arabidopsis ${ }^{13}$. It has been shown that PAMPs induce SA biosynthesis in an ICS1-dependent manner ${ }^{14,15}$. Interestingly, the flg22-induced early expression of PAD4,EDS5, PBS3 and ICS1, all of which are essential for SA biosynthesis, was significantly reduced in cas-1 plants before SA accumulation ( 1 h; Fig. $4 \mathrm{f})$. On the other hand, PR1 expression was induced significantly by SA in cas-1 plants similarly to in wild-type plants (Supplementary Fig. S10), indicating that the signal transduction pathways downstream of SA are independent of CAS. These results demonstrate that CAS is involved in flg22-induced SA biosynthesis through promoting the expression of nuclear-encoded SA biosynthesis genes.

CAS-dependent induction of nuclear-encoded defence genes. These findings led us to hypothesize that CAS may be involved in chloroplast-to-nucleus retrograde signalling to control the expression of nuclear-encoded defence genes, including SA biosynthesis 
a

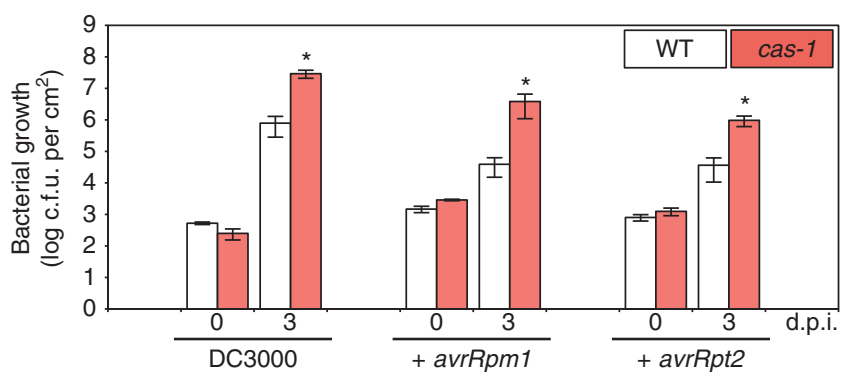

C

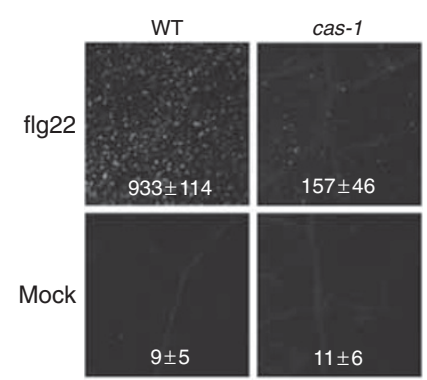

d

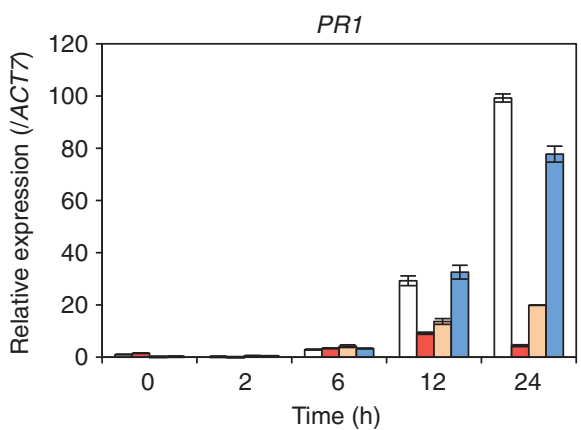

b

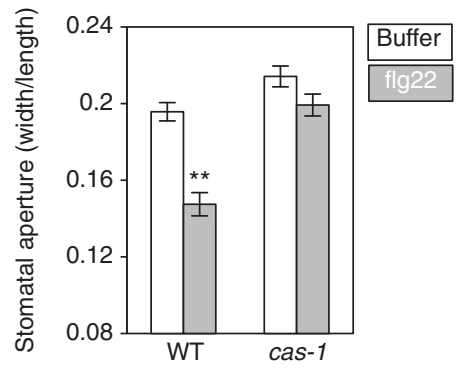

e

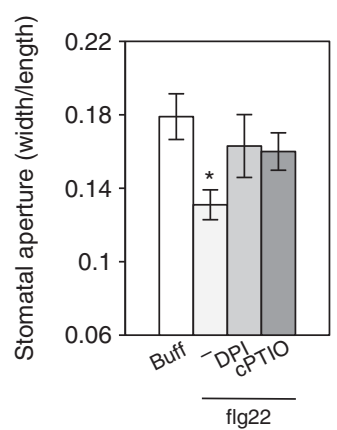

f

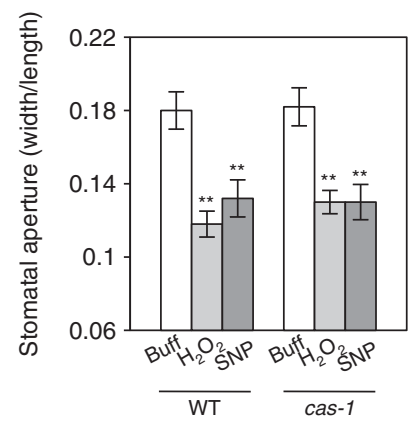

PR2

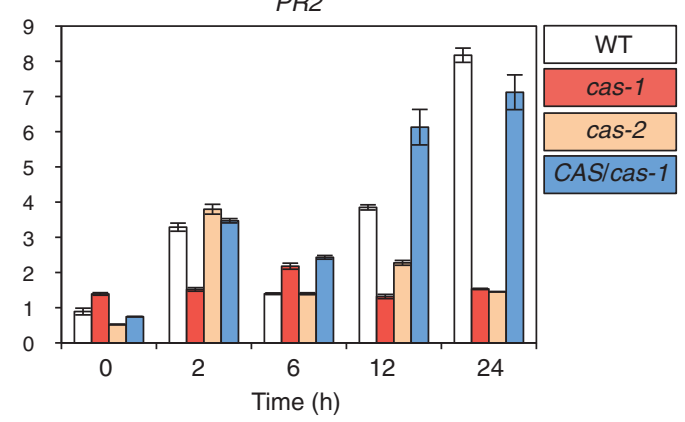

Figure 2 | Defects of immune regulation in cas-1 mutants. (a) Bacterial growth of Pseudomonas syringae pv. tomato (Pst) in Arabidopsis leaves. Wild-type (WT) or cas-1 plants were inoculated with virulent or avirulent Pst DC3000 $\left(\mathrm{OD}_{600}=0.0001\right)$, and numbers of bacteria per leaf area on days 0 and 3 were plotted on a log scale. Data are the means \pm s.e.m. of relative values $\left(n=4 ;{ }^{\star} P<0.05\right.$, Student's $t$-test). The experiment was repeated three times, with similar results; d.p.i., days post infection. (b) Flg22-induced stomatal closure. The stomatal aperture was calculated as the ratio of the pore width/ guard cell length. Data are the means \pm s.e.m. of 50 stomata from three replicates ( ${ }^{\star \star} P<0.01$, Tukey-Kramer HSD test). (c) Detection of flg22-induced callose deposition with aniline blue. Representative pictures and the average number (with SD) of callose deposits per $4.5 \mathrm{~mm} \mathrm{~m}^{2}(n=8)$ are shown. The experiment was repeated three times, with similar results. (d) Flg22-induced gene expression was analysed by qRT-PCR at the indicated time points. ACT7 was used as an internal standard. Data are means \pm s.e.m. of relative values $(n=3)$. (e) Flg22-induced stomatal closure was inhibited in the presence of DPI or CPTIO. Leaves were pre-incubated with buffer (Buff) containing DPI or CPTIO for 30 min and then treated with $5 \mu \mathrm{M} f l g 22 \mathrm{for} 2 \mathrm{~h}$. (f) Exogenously applied $\mathrm{H}_{2} \mathrm{O}_{2}$ and SNP could induce stomatal closure in cas-1. The stomatal aperture was calculated as the ratio of pore width/guard cell length. Data are the means \pm s.e.m. of 50 stomata (e: ${ }^{\star} P<0.05$, f: ${ }^{\star \star} P<0.01$, Tukey-Kramer HSD test).

genes. Flg22 induces the expression of numerous defence-related genes in the nucleus ${ }^{15,16}$. To identify flg22-induced genes that are under the control of CAS, an Arabidopsis gene expression microarray (v4) was used to compare the flg22-induced transcription profiles of wild-type and cas-1 plants. We identified 687 upregulated and 1,235 downregulated genes in cas-1 plants treated with flg22 for $2 \mathrm{~h}$ (Fig. 5a and Supplementary Data 1 and 2). By contrast, only 7 genes were upregulated and 197 genes were downregulated in non-treated cas-1 plants (Fig. 5a and Supplementary Data 3 and 4). In all, 121 of the 197 downregulated and 6 of the 7 upregulated genes in non-treated cas-1 plants were also down- and upregulated in flg22-treated cas-1 plants, respectively. Quantitative reverse transcription-PCR (qRT-PCR) confirmed the array results for selected targets (Figs $4 \mathrm{f}$ and $5 \mathrm{c}$ ). Interestingly, the expressions of one-third (827 genes) of the flg22-induced early genes (within $3 \mathrm{~h})^{17}$ were suppressed in cas-1 (Fig. 5a,b, Supplementary Fig. S11). Similarly, two-thirds of genes downregulated in flg22-treated cas-1 were flg22induced in wild type. Furthermore, the 403 genes upregulated in flg22-treated cas-1 were enriched for genes that were suppressed by flg22 in wild type (58.7\%). Gene expression analysis using the Expression Browser at Bio-Array Resource (BAR) ${ }^{18}$ showed that genes downregulated in flg22-treated cas-1 were also enriched in NPP1- and HrpZ-responsive genes, as well flg22-responsive genes (Supplementary Fig. S12a). CAS, therefore, likely has a universal role in PAMP-induced gene expression.

Gene ontology analysis using the Arabidopsis Classification Super Viewer demonstrated a significant over-representation of 'response to stress' (3.04-fold, $P=5.33 \mathrm{E}-50$ ), 'response to abiotic and biotic stimulus' (2.49-fold, $P=2.83 \mathrm{e}-28)$ and signal transduction (2.26-fold, $P=7.17 \mathrm{e}-14)$ categories among the flg22-treated 


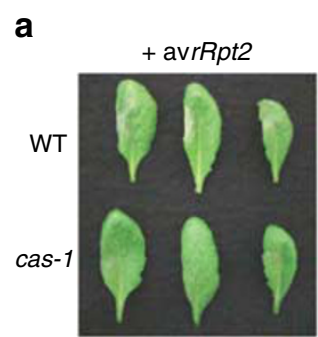

C

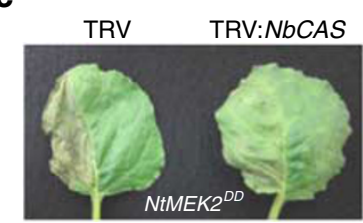

b

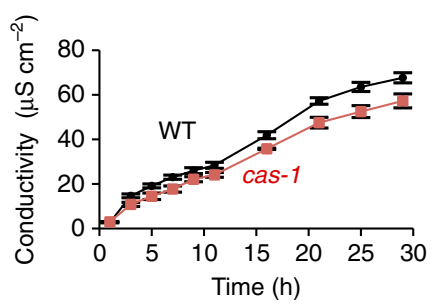

d

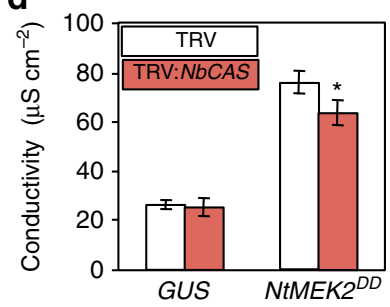

Figure 3 | CAS-dependent hypersensitive response (HR) cell death. $(\mathbf{a}, \mathbf{b}) \mathrm{HR}$ after inoculation with avirulent Pseudomonas syringae pv. tomato (Pst) DC3000 (avrRpt2) $\left(\mathrm{OD}_{600}=0.05\right)$. (a) HR lesions on the left side of leaves at $14 \mathrm{~h}$. (b) lon leakage after inoculation was measured at the indicated time points in leaves of wild-type (WT; black line) and cas-1 knockout (red line) plants. Data are the means \pm s.e.m. of six discs from three replicates. (c) NbCAS-silenced $N$. benthamiana plants display a delay of cell death. Four- to five-week-old NbCAS-silenced plants were infiltrated with Agrobacterium containing the NTMEK2 ${ }^{D D}$ expression vector. Tobacco rattle virus (TRV) was used as an experimental control. Pictures are taken at 3 days after inoculation. (d) lon leakage at 3 days after infiltration with Agrobacterium containing GUS or NtMEK2 ${ }^{D D}$ was measured in silenced leaves. Data are the means \pm s.e.m. of six discs from three replicates. Significance was determined using Student's $t$-test $\left({ }^{\star} P<0.05\right)$.

cas-1 downregulated genes (Supplementary Fig. S12b-e). The downregulated genes included a number of GTPase, $\mathrm{Ca}^{2+}$ signalling and SA signalling genes (Supplementary Data 5). CAS was also required for flg22-induced expression of CYP79B2, CYP79B3 and PAD3 genes for cytochrome $\mathrm{P} 450$ that are essential for the production of camalexin, the charateristic phytoalexin of Arabidopsis. On the other hand, the flg22-treated cas-1 upregulated genes were enriched for those involved in 'electron transport or energy pathways' (2.34-fold, $P=1.34 \mathrm{e}-3)$. Interestingly, genes for plastid (1.93-fold, $P=1.46 \mathrm{e}-5$ ) and chloroplast (1.86-fold, $P=5.29 \mathrm{e}-12)$ proteins were significantly enriched among the upregulated genes in flg22-treated cas-1. These results suggest that chloroplasts may promote defence gene expression and suppressing chloroplast (photosynthesis) gene expression through CAS during PTI.

Chloroplast regulation of nuclear transcriptional programmes. We identified 99 and 78 transcription factor (TF) genes among the downregulated and upregulated genes in cas-1, respectively. WRKYs are a large family of plant-specific TFs (with 72 genes in Arabidopsis) that act mainly in the defence response network of plant cells ${ }^{19,20}$. We identified one-third of WRKY genes under the control of CAS (25 downregulated and 1 upregulated; Supplementary Data 1), suggesting an important role for WRKYs in CAS-dependent PTI. In fact, the most represented motif in the promoters (500-bp upstream regions) of the flg22-treated cas-1 downregulated genes was TTGAC (Supplementary Table S1). TTGAC is part of the W-box consensus sequence (TTGAC[C/T]) of the WRKY-binding site ${ }^{19}$. The $\mathrm{W}$-box motif was found in the promoters of 539 of the 1,235 genes downregulated in flg22-treated cas-1 (44\%). The W-box sequences were enriched in the promoter region at 200-400 bp upstream of the translation start site (Supplementary Fig. S13), confirming the
W-box as a cis-element of the flg22-treated cas-1 downregulated (CAS-dependent) genes. The flg22-treated cas-1 downregulated TFs included several key factors, such as WRKY33 relaying the MAPK signal to the transcription network in $\mathrm{PTI}^{19}$, and WRKY28/WRKY46 (ref. 21) and CBP60g/SARD1 (ref. 22), essential for the activation of ICS1 and SA synthesis. Taken together, WRKY TFs might have a critical role in PAMP (flg22)-induced chloroplast-mediated transcriptional reprogramming in plant innate immunity.

By contrast, the upregulated TF genes included AtGLK2 (ref. 23), CIA2 (ref. 24), GATA21(GNC) ${ }^{25}$ and a set of chloroplast sigma factors (AtSIG1, AtSIG3, AtSIG4 and AtSIG6), which are required for chloroplast development ${ }^{26}$. Interestingly, the I-box motif involved in light-responsive photosynthetic gene expression ${ }^{27}$ was found in the promoters of 149 of the 687 genes upregulated in flg22-treated cas-1 plants. Thus, it seems that chloroplasts (CAS) regulate plant immune responses through activation of defence-related TFs and suppression of chloroplast function/development by inactivating TFs required for chloroplast development.

Chloroplast-derived ROS and CAS-dependent gene expression. To examine the role of flg22-induced TFs during early PTI, we performed a time course expression analysis using qRT-PCR. PAMP (flg22) triggered a rapid (within $15 \mathrm{~min}$ ) and transient increase in the expression of TF genes such as CBP60g, WRKY28, WRKY33 and MYB122 (Fig. 5c), suggesting a role for them in early transcriptional reprogramming during PTI. On the other hand, the expression of WRKY75 (Fig. 5c) and SA biosynthesis-related genes (Fig. 4f) peaked at $1-2 \mathrm{~h}$, and $P R 1$ gene expression was induced after $12 \mathrm{~h}$. Interestingly, flg22-induced early expression of TF genes (within $30 \mathrm{~min}$ ) was not suppressed in cas-1 mutants, but CAS was needed for the middle phase (1-2h) expression of TF (Fig. 5c) and SA biosynthesis-related genes (Fig. 4f), and PR1 gene expression at the late phase $(24 \mathrm{~h})$. On the other hand, overexpression of CAS hastened and enhanced early expression of a set of TF genes such as CBP60g, WRKY33 and MYB122 (Fig. 5c), suggesting a possible activating role of CAS in defence-related TF gene expression. These results imply that after a $\sim 30$-min lag chloroplasts may generate CAS-dependent retrograde signals, which is required for prolonged expression of the early defence-related TFs and promotes subsequent expression of defence-related genes. It has been proposed that chloroplast-derived ROS signals, such as ${ }^{1} \mathrm{O}_{2}$ and $\mathrm{H}_{2} \mathrm{O}_{2}$, may activate the expression of nuclear-encoded defence genes ${ }^{28,29}$. Notably, we found that 427 of 1,235 genes downregulated in flg22treated cas-1 overlapped with genes that were ${ }^{1} \mathrm{O}_{2}$-responsive in the flu mutant (fold change $>3.0$ ), including several ${ }^{1} \mathrm{O}_{2}$ marker genes, EDS5 and ERD1 (Fig. 5b and Supplementary Data 1) ${ }^{29}$. By contrast, only 153 genes overlapped with methyl viologen (MV)-induced $\mathrm{O}_{2}{ }^{-} / \mathrm{H}_{2} \mathrm{O}_{2}$-responsive genes (fold change $>3.0$; Supplementary Data 1$)^{30}$. These results suggest a role for CAS in ${ }^{1} \mathrm{O}_{2}$ signalling to control nuclear-encoded defence gene expression.

\section{Discussion}

CAS is a plant-specific low-affinity/high-capacity non-EF-hand $\mathrm{Ca}^{2+}$-binding protein that is associated with thylakoid membranes of chloroplasts (Supplementary Fig. S14) ${ }^{8-10,12}$. This study demonstrates that the chloroplast protein CAS is required for both PTI and $R$ gene-mediated ETI. PTI and ETI are controlled by complex interconnected signalling networks including the MAP kinase cascade, ROS signalling and the plant hormones SA, JA and ethylene $^{1,2}$. We found that CAS may act upstream of ROS signalling in PAMP-induced stomatal closure, and downstream of the MAP kinase cascade and upstream of ROS/NO in ETI (Figs $2 \mathrm{f}, 3 \mathrm{c}$ and Supplementary Fig. S6). Furthermore, we demonstrated that CAS is required for the flg22-induced accumulation of SA (Fig. 4). Considering the chloroplast localization of CAS, these findings suggest that chloroplasts have a critical role in both PTI and ETI. CAS may 


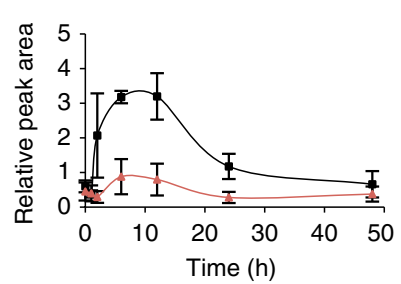

b
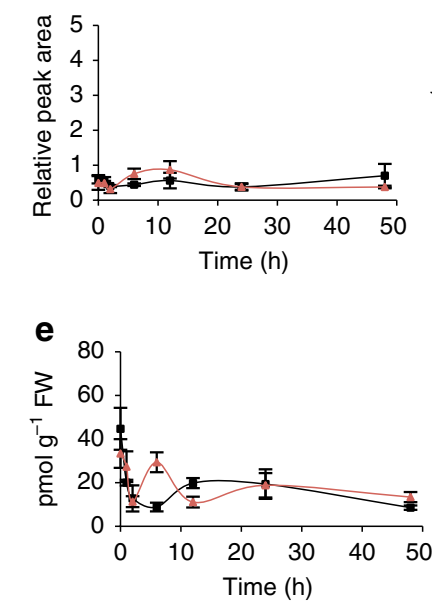

C

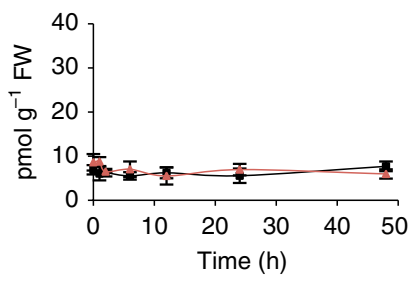

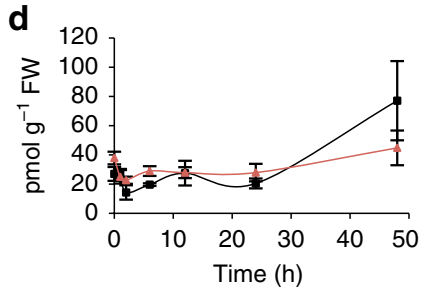

f
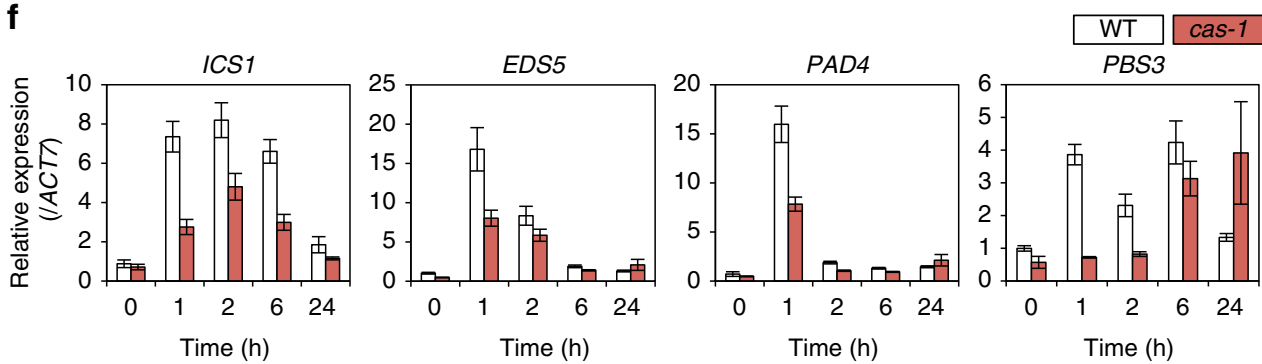

Figure 4 | CAS regulates salicylic acid (SA) biosynthesis and its related gene expression. (a-e) Flg22-induced phytohormone accumulation was measured at the indicated time points in leaves of wild-type (black line) and cas- 1 knockout (red line) plants. Data are the means \pm s.e.m. of three experiments. (a) SA and (b) jasmonic acid (JA) accumulation were measured using UPLC/TOFMS, and (c) abscisic acid (ABA), (d) indole-3-acetic acid (IAA) and (e) cytokinins were measured using nano-LC/MS/MS, and has been shown as the amount of hormones per fresh weight (FW) of plants. (f) Flg22-induced gene expression was analysed at indicated time points by $\mathrm{qRT}$-PCR. ACT7 was used as an internal standard. Data are mean \pm s.e.m. of three experiments.

be involved in the coupling of chloroplasts and cellular immune responses and may function upstream of ROS signalling and SA biosynthesis.

We found that CAS is required for transcriptional activation of SA biosynthesis genes, such as ICS1, EDS5, PBS3 and PAD4, whereas the SA signalling pathway downstream of SA is not impaired in cas-1 plants (Fig. 4 and Supplementary Fig. S10). Furthermore, microarray analysis revealed that the expression of a set of TF genes (WRKY28/WRKY46 and CBP60g/SARD1) 21,22 , essential for activation of SA biosynthesis genes, was greatly reduced in cas-1 plants (Supplementary Data 1). These results suggest that CAS mediates the chloroplast control of SA biosynthesis through these TFs, and the resultant SA subsequently induces a range of basal defence responses. On the other hand, considering the co-localization of CAS and SA biosynthesis in chloroplasts, there remains a possibility that CAS might directly modulate ICS1 activity within chloroplasts.

Recognition of pathogens results in a massive reprogramming of plant cells to activate defence responses and reduce other cellular activities, such as cellular development/organization and photosynthesis ${ }^{31}$. Microarray analysis demonstrates that CAS controls transcriptional reprogramming during PTI through activation of defence-related TFs including a number of WRKYs and suppression of TFs involved in chloroplast development. We found that a short DNA motif, W-box (TTGAC[T/C]), is over-represented in the promoter sequences of flg22-treated cas- 1 downregulated (CASdependent flg22-induced) genes (52.6\%). The WRKY family TFs regulate biotic and abiotic stress responses and share the WRKY domain that recognizes the $\mathrm{W}$-box ${ }^{19}$. Interestingly, the $\mathrm{W}$-box is over-represented not only in the promoter regions of defence-related genes, but also in $\mathrm{O}_{3}$-responsive ${ }^{32}$ and superoxide-responsive promoters ${ }^{30}$. On the other hand, some promoters of CAS-dependent flg22-suppressed genes contain an I-box motif, a common ciselement characteristic of photosynthesis genes (Supplementary Table S1) ${ }^{27}$. Thus, these results suggest that CAS-dependent defence gene expression might be mediated by WRKY TFs that target W-box-containing promoters of plant defence genes in a ROSdependent manner, whereas CAS may control PAMP-induced suppression of photosynthesis gene expression via an I-box-binding protein/I-box-mediated transcription system. Interestingly, some TF genes occur more rapidly in CAS-overexpressing plants, suggesting a direct role for CAS in the promotion of defence-related TF gene expression. However, the molecular function of CAS remains largely unknown. CAS deficiency may disrupt unidentified chloroplast function related to defence responses and indirectly affect the expression pattern of flg22-induced defence genes. Nevertheless, these findings strongly suggest that chloroplasts have a critical role in the transcriptional regulation of plant immune signalling.

It has been proposed that chloroplast-derived retrograde signals, such as chlorophyll synthesis intermediates and chloroplast-derived ROS, control the expression of nuclear-encoded genes for photosynthesis and defence responses ${ }^{33}$, respectively. When the cell is unable to dissipate excess excitation energy, chloroplasts generate ROS, such as singlet oxygen $\left({ }^{1} \mathrm{O}_{2}\right)$ or hydrogen peroxide $\left(\mathrm{H}_{2} \mathrm{O}_{2}\right)$, which activate distinct sets of genes. Interestingly, ${ }^{1} \mathrm{O}_{2}$ triggers a cell death programme that resembles the effector-triggered $\mathrm{HR}^{34}$. Here, we found that almost one-third of CAS-dependent flg22-induced genes are also induced by ${ }^{1} \mathrm{O}_{2}$ in the flu mutant (Fig. 5b), but not by 
a

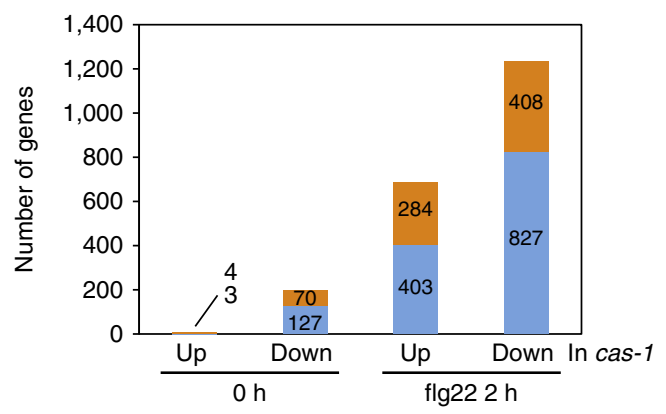

b

Downregulated in flg22-treated cas-1 (WT/cas-1 up) $(1,235)$

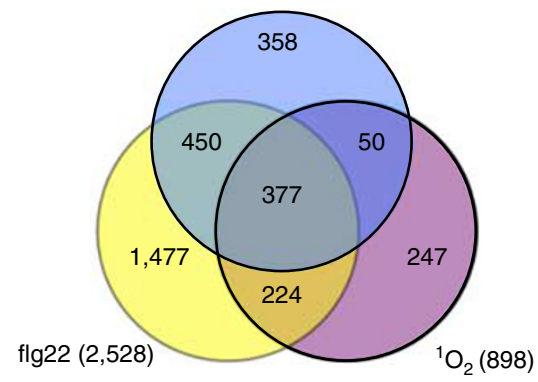

C
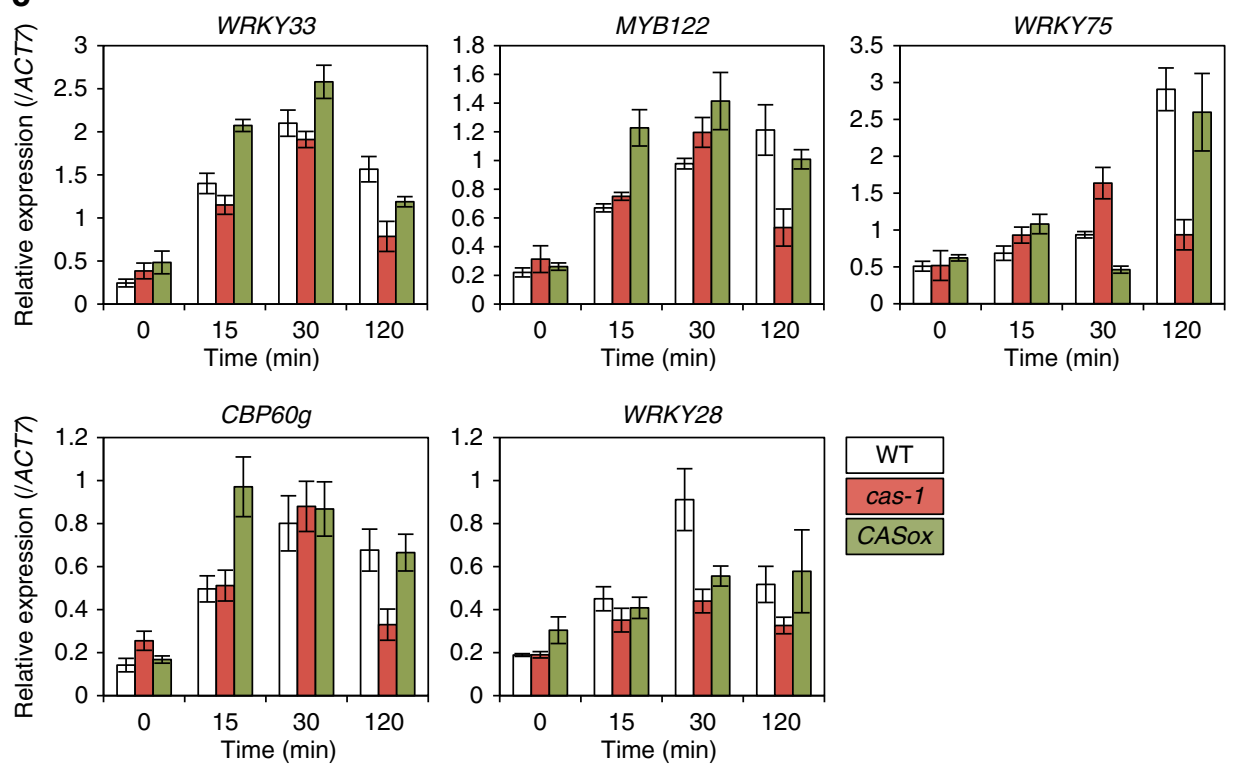

Figure 5 | Genome-wide transcriptional analysis of cas-1 mutants in flg22-induced immunity. (a) Numbers of differentially expressed genes that were up- or downregulated in cas-1 plants treated with flg22 for $2 \mathrm{~h}$ (right) or not treated (left). Genes that were regulated by flg22 within $3 \mathrm{~h}$ are shown in blue. Several flg22-induced genes were downregulated before flg22 treatment in cas-1 plants. (b) Venn diagram showing the overlap of downregulated genes in flg22-treated cas-1 (WT/cas-1 up: blue), flg22-induced genes within $3 \mathrm{~h} \mathrm{(flg22:} \mathrm{yellow)} \mathrm{and} \mathrm{chloroplastic}{ }^{1} \mathrm{O}_{2}$-dependent genes under light for $2 \mathrm{~h}$ in the flu mutant background $\left({ }^{1} \mathrm{O}_{2}\right.$ : purple). (c) Expression of flg22-induced genes was analysed at indicated time points by qRT-PCR to confirm microarray experiments. ACT7 was used as an internal standard. Data are mean \pm s.e.m. of three experiments. WT, wild type.

MV-induced $\mathrm{H}_{2} \mathrm{O}_{2}$. Furthermore, CAS-dependent flg22-induced genes also overlap with the light-induced genes in flu mutants overexpressing thylakoid-localized ascorbate peroxidase, which is expected to compensate for chloroplast-derived $\mathrm{O}_{2}{ }^{-}$and $\mathrm{H}_{2} \mathrm{O}_{2}$, but not ${ }^{1} \mathrm{O}_{2}$ (ref. 29). These results suggest a role for chloroplast-derived ${ }^{1} \mathrm{O}_{2}$ signalling in CAS-dependent transcriptional control of nuclearencoded defence genes. Moreover, the flg22-induced extracellular ROS burst was not impaired in cas-1 plants (Supplementary Fig. S15), suggesting a limited role of NADPH oxidase-derived $\mathrm{O}_{2}{ }^{-}$and $\mathrm{H}_{2} \mathrm{O}_{2}$ in CAS-dependent immune responses. In addition, it has been recently shown by another group that extracellular $\mathrm{Ca}^{2+}$-induced generation of chloroplast NO and ROS is dependent on CAS, but not plasma membrane-localized NADPH oxidase ${ }^{35}$, providing further confirmation of the role of CAS in ROS production in chloroplasts. Thus, we assume that CAS may be involved in the chloroplast-derived ${ }^{1} \mathrm{O}_{2}$-mediated retrograde signalling that regulates the expression of nuclear-encoded defence-related genes at an early stage in PTI. In fact, the release of ${ }^{1} \mathrm{O}_{2}$ in the flu mutant triggers the expression of WRKY33 and WRKY46 TFs during the first $30 \mathrm{~min}$ of reillumination ${ }^{36}$, a subsequent drastic increase in free SA levels, and the expression of $P R 1$ and $P R 5$ genes ${ }^{37}$. Time course qRT-PCR analysis revealed that chloroplasts generate signal(s) after a $30-\mathrm{min}$ lag time. Interestingly, it has been reported that Cle elicitor induces ${ }^{1} \mathrm{O}_{2}$ in cultured cells after a $10-\mathrm{min}$ lag period, and peaks at $30 \mathrm{~min}$ after the treatment ${ }^{38}$. This time course coincides well with those of flg22-induced defence-related gene expression and subsequent SA biosynthesis. We propose that a CAS-dependent chloroplastderived signal (possibly ${ }^{1} \mathrm{O}_{2}$ ) may modulate the defence responses through transcriptional reprogramming of defence-related genes.

Therefore, it is speculated that pathogen signals are transmitted to chloroplasts before the production of chloroplast-derived ROS signal(s). Sai and Johnson ${ }^{11}$ previously reported that light-todark transition triggers a transient rise of stromal free $\mathrm{Ca}^{2+}$ levels in tobacco chloroplasts. Here, we show that PAMPs evoke a longlasting stromal $\mathrm{Ca}^{2+}$ increase following a rapid cytoplasmic $\mathrm{Ca}^{2+}$ transient (Fig. 1a,b). It is known that the thylakoid lumen accumulates $\mathrm{Ca}^{2+}$ at a high level. CAS is responsible for the full activation of long-lasting stromal $\mathrm{Ca}^{2+}$ transients induced by flg 22 and darkness (Fig. 1i,j). Thus, it is plausible that CAS regulates the release and/or uptake of $\mathrm{Ca}^{2+}$ through thylakoid membranes to evoke long-lasting stromal $\mathrm{Ca}^{2+}$ signals. We further demonstrate that several abiotic stresses also induce stress-specific stromal $\mathrm{Ca}^{2+}$ signals (Fig. 1d-f), suggesting that stromal $\mathrm{Ca}^{2+}$ signatures may be involved in stressspecific responses, including rapid inhibition of photosynthesis and 


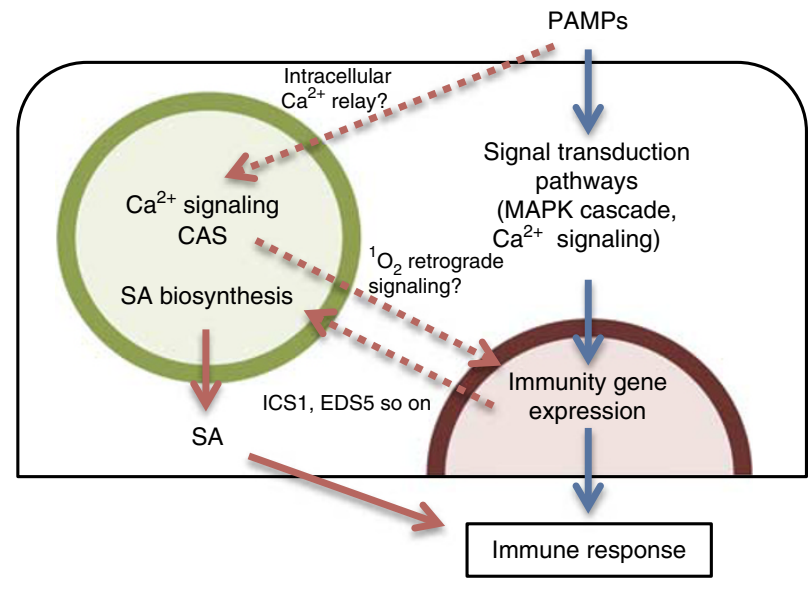

Figure 6 | Molecular cross talk between chloroplasts and cytoplasmicnuclear immune system. Pathogen-associated molecular pattern (PAMP) signals are quickly relayed to chloroplasts and evoke specific $\mathrm{Ca}^{2+}$ signatures in the stroma. The thylakoid-associated calcium sensor protein CAS is involved in the generation of chloroplast $\mathrm{Ca}^{2+}$ signals. CAS is also essential for the induction of PAMP-induced defence genes, including salicylic acid (SA) biosynthesis genes, possibly through singlet oxygen $\left({ }^{1} \mathrm{O}_{2}\right)$-mediated retrograde signalling, Thus, SA-mediated immune responses are dependent on CAS. Chloroplast-mediated pathways involved in the communication between chloroplasts and the cytoplasmicnuclear signal transduction pathways are shown as dotted red arrows. The cytoplasmic and SA-mediated immune pathways are shown as red and blue arrows, respectively.

accumulation of $\mathrm{JA}^{39,40}$. Interestingly, chloroplasts contain several EF-hand $\mathrm{Ca}^{2+}$ sensor proteins and other types of $\mathrm{Ca}^{2+}$-binding proteins ${ }^{41}$.

PAMP-induced stromal $\mathrm{Ca}^{2+}$ transients precede CAS-dependent defence gene expression and SA biosynthesis, suggesting a role for chloroplast $\mathrm{Ca}^{2+}$ signatures in the activation of defence gene expression. Interestingly, genes induced by some abiotic stimuli such as light-to-dark transition and osmotic stress, which evoke long-lasting stromal $\mathrm{Ca}^{2+}$ signals, were enriched among genes downregulated in flg22-treated cas-1, but cold and salt-induced genes were not (Supplementary Fig. S16). The W-box sequences were also overrepresented in the promoter regions of genes upregulated by osmotic stress, but not of cold and salt stimili-induced genes (Supplementary Tables S1 and S2). Thus, chloroplast $\mathrm{Ca}^{2+}$ signatures are likely involved in stress-specific gene expression. It has been shown that $\mathrm{Ca}^{2+}$ regulates FBPase ${ }^{42,43}$, and the stability of the photosystem II and thylakoid $\mathrm{O}_{2}$ evolving complexes ${ }^{44}$. The stromal $\mathrm{Ca}^{2+}$ transients coincide with the stress-induced rapid downregulation of photosynthesis ${ }^{39,45,46}$. Importantly, photosynthesis collapse may lead to photo-induced production of ROS including ${ }^{1} \mathrm{O}_{2}$ (ref. 47). Taken together, long-lasting stromal $\mathrm{Ca}^{2+}$ signals may induce the downregulation of photosynthetic electron flow, leading to the production of ROS. Interestingly, cas-1 mutants show higher values of nonphotochemical chlorophyll fluorescence quenching than do wild-type plants $^{8}$. Non-photochemical chlorophyll fluorescence quenching has a major role in the protection of the photosynthetic apparatus against damage by excess light and the production of $\mathrm{ROS}^{48}$.

Herein, we demonstrated a novel chloroplast-dependent pathway that controls plant innate immunity through stromal $\mathrm{Ca}^{2+}$ signalling and chloroplast-to-nuclei retrograde ROS signalling (Fig. 6). Recent studies have shown that plant innate immune responses are modified by light and intrinsic circadian cues ${ }^{49,50}$. Chloroplasts may act as an environmental sensor in plants ${ }^{51}$. Interestingly, CAS is required for photoacclimation in Chlamydomonas ${ }^{12}$.
Furthermore, CAS has been shown to be involved in the coupling of diurnal extracellular $\mathrm{Ca}^{2+}$ oscillations to cytosolic $\mathrm{Ca}^{2+}$ oscillations ${ }^{52}$. Characterization of the molecular function of CAS and chloroplast $\mathrm{Ca}^{2+}$ signalling would provide insight into the role of chloroplasts in cross talk among environmental regulation pathways and plant immunity.

\section{Methods}

Plant materials and growth conditions. Arabidopsis thaliana wild-type Columbia ecotype, CAS knockout mutants (cas-1 and cas- 2$)^{8}$, CAS-overexpressing plants ${ }^{8}$ and apoaequorin transgenic plants were germinated and grown on one-half Murashige and Skoog (MS) medium containing $0.8 \%(\mathrm{w} / \mathrm{v})$ agar at $22^{\circ} \mathrm{C}$ with $16-\mathrm{h}$ light $\left(80-100 \mu \mathrm{mol} \mathrm{m}^{-2} \mathrm{~s}^{-1}\right) / 8$-h dark cycles for 2-4 weeks. For pathogen inoculation experiments, 4- to 5-week-old wild-type and cas-1 plants grown on soil with 10-h light (140-160 $\left.\mu \mathrm{mol} \mathrm{m}^{-2} \mathrm{~s}^{-1}\right) / 14$-h dark cycles were used.

Measurements of cytosolic and stromal $\mathrm{Ca}^{2+}$ concentrations. $\mathrm{Ca}^{2+}$ measurements were performed as previously described, with some modifications ${ }^{8}$. Detached rosette leaves from plate-grown transgenic wild-type and cas-1 Arabidopsis plants expressing aequorin were floated on one-half MS liquid medium containing $5 \mu \mathrm{M}$ coelenterazine, then kept overnight at $22^{\circ} \mathrm{C}$ in the dark. Aequorin luminescence was measured with Lumi Counter 2500 (Microtec). The amount of reconstituted aequorin in the plants was determined by the addition of an equal volume of $2 \mathrm{M} \mathrm{CaCl}_{2}$ in $20 \%$ ethanol at the end of the measurements. Aequorin luminescence calibration was performed as previously described ${ }^{53}$.

Elicitor peptide flg22 was synthesized by Biologica(Nagoya). The chitin suspen sion was prepared as previously described ${ }^{54}$. Chitin (Wako) was hydrolysed with concentrated $\mathrm{HCl}$, and left for $2 \mathrm{~h}$ at room temperature with occasional mixing. The hydrolysed chitin was then washed with water twice, and dissolved in one-half MS medium to achieve a final chitin concentration of $1.0 \mathrm{mg} \mathrm{ml}^{-1}$. Cold shock stress was applied to the plants by adding ice-cold one-half MS medium to a leaf floated in a cuvette. The measurement of dark-stimulated $\mathrm{Ca}^{2+}$ changes was performed as described ${ }^{11}$. Ten-day-old plants were incubated at $22^{\circ} \mathrm{C}$ under 24 -h light conditions $\left(22 \mu \mathrm{mol} \mathrm{m}^{-2} \mathrm{~s}^{-1}\right)$, and then transferred to the dark. In pharmacological experiments, BAPTA (Wako), K-252a (Wako), U-0126 (Calbiochem) or DPI (Calbiochem) were dissolved in ethanol or DMSO and applied to plants in a cuvette at the appropriate concentration and left for $30 \mathrm{~min}$ before treatment with flg 22 .

Plant inoculation and quantification of bacteria. Pathogen inoculations, bacterial growth counts and ion conductance measurements were performed as previously described, with some modifications ${ }^{55}$. The virulent strain of Pst DC3000 and avirulent strains of Pst DC3000 (carrying avrRpt2 or avrRpm1) were cultured at $28^{\circ} \mathrm{C}$ in King's B medium containing $25 \mu \mathrm{g} \mathrm{ml}^{-1}$ kanamycin, $100 \mu \mathrm{g} \mathrm{ml}^{-1}$ rifampicin and $50 \mu \mathrm{g} \mathrm{ml}^{-1}$ cycloheximide, washed once in $10 \mathrm{mM} \mathrm{MgCl}_{2}$ and resuspended in $10 \mathrm{mM} \mathrm{MgCl}_{2}$. Needleless syringe infiltration was used to inoculate plants with pathogen in all cases. Immediately after the infiltration, the plants were allowed to dry and were then kept under $100 \%$ humidity for the remainder of the experiment. At indicated time points, leaf discs were collected, ground to homogeneity in water and the titre was determined by serial dilution and plating.

For measurements of ion leakage, 6 leaf discs (8-mm diameter) were removed immediately following infiltration $(t=0)$ and floated in $25 \mathrm{ml}$ of water. After $30 \mathrm{~min}$, the water was removed and replaced with $10 \mathrm{ml}$ of new water. The conductance of this water was measured at the indicated time points.

Stomatal aperture measurements. Stomatal aperture measurements were performed as previously described ${ }^{8}$. Rosette leaves from 3- to 4 -week-old plate-grown plants were detached and floated on the incubation buffer $(10 \mathrm{mM} 2-(\mathrm{N}-$ morpholi no)ethanesulfonic acid (MES)-KOH, $\mathrm{pH} 6.15 ; 10 \mathrm{mM} \mathrm{KCl} ; 50 \mu \mathrm{M} \mathrm{CaCl}_{2}$ ) for $2 \mathrm{~h}$ at $22^{\circ} \mathrm{C}$, in $80-100 \mu \mathrm{mol} \mathrm{m}^{-2} \mathrm{~s}^{-1}$ light. After $2 \mathrm{~h}$, the leaves in the incubation buffer were treated with or without $5 \mu \mathrm{M}$ flg $22,10 \mu \mathrm{M} \mathrm{H}_{2} \mathrm{O}_{2}$ or $50 \mu \mathrm{M}$ SNP and then incubated for an additional $2 \mathrm{~h}$. For inhibitor experiments, the leaves were preincubated with $50 \mu \mathrm{M}$ DPI or $200 \mu \mathrm{M}$ cPTIO for $30 \mathrm{~min}$ before treatment with flg22. After the incubation period, epidermal strips of the leaves were observed by microscopy. The stomatal aperture was calculated as the ratio of the pore width/ guard cell length. A guard cell length of $22-28 \mu \mathrm{m}$ was used in the experiments.

Callose deposition. Rosette leaves of 4- to 5-week-old soil grown wild-type and cas-1 plants were infiltrated with $10 \mathrm{mM}$ Tris- $\mathrm{HCl}$ ( $\mathrm{pH} 7.2$; mock) or the same solution containing $5 \mu \mathrm{M}$ flg22. After $24 \mathrm{~h}$, the leaves were detached, cleared with ethanol and stained with $10 \mathrm{mM}$ Tris- $\mathrm{HCl}(\mathrm{pH} 7.2)$ containing $0.01 \%$ aniline blue for $30 \mathrm{~min}$. Leaves were stored in 50\% glycerol and observed via epifluorescence microscopy under UV illumination with a broadband DAPI filter set. Measurements of callose deposition were made using the image-processing software IMAGEJ.

Metabolite analysis by nano-LC/MS/MS and UPLC/TOFMS. Levels of SA, JA, ABA, IAA, zeatin and zeatin riboside were analysed by nano-liquid chromatography - tandem mass spectrometry (LC/MS/MS) with a modification 
of the methods described by Izumi et al. ${ }^{56}$. Briefly, $100 \mathrm{mg}$ of leaf samples were homogenized using a ballmill and extracted with methanol/ $\mathrm{H}_{2} \mathrm{O} /$ formic acid (75:20:5) solution containing internal standards ( $40 \mathrm{pmol}\left(\mathrm{d}_{7}-\mathrm{DHZOG}, \mathrm{d}_{3}-\mathrm{DHZR}\right.$, $\left.\mathrm{d}_{6}-\mathrm{iP}, \mathrm{d}_{6}-\mathrm{iPR}\right), 200 \mathrm{pmol}\left(\mathrm{d}_{6}-\mathrm{ABA}\right), 400 \mathrm{pmol}\left(\mathrm{d}_{3}-\mathrm{DHZ}\right), 1,000 \mathrm{pmol}\left(\mathrm{d}_{2}-\mathrm{GA}_{1}\right.$, $\mathrm{d}_{5}$-IAA, $\left.\mathrm{d}_{2}-\mathrm{GA}_{7}\right), 2 \mu \mathrm{mol}$ lidocaine and $10 \mu \mathrm{mol}(+)$-10-camphorsulfonic acid). After centrifugation, half of the supernatant was used for analyses of SA, JA and small charged molecules by ultra-performance liquid chromatography - timeof-flight mass spectrometry (UPLC/TOFMS) as described previously ${ }^{56,57}$. The remaining supernatant was extracted with water and dried. The dried samples were dissolved in $1 \mathrm{M}$ formic acid and applied to the OASIS MCX cartridge. The fraction containing $\mathrm{ABA}$ and IAA was eluted with methanol and, subsequently, the $\mathrm{CK}$ fraction was eluted with $60 \%$ methanol solution containing $0.35 \mathrm{M} \mathrm{NH}_{4}$. Eluted fractions were further purified and analysed by nano-LC/MSMS.

SA was also measured using a conventional high-performance liquid chromatography system. A total of $200 \mathrm{mg}$ of seedling samples without roots was homogenized and extracted with $100 \%$ methanol containing the internal standard anisic acid. Free and glycosylated SA were separated and analysed by high-performance liquid chromatography.

VIGS and Agrobacterium-mediated transient expression. VIGS was done as described by Ratcliff $e$ e $a l .{ }^{58}$. pBINTRA6 (RNA1) and the pTV00 containing the $\mathrm{NbCAS}$ cDNA fragment (RNA2) were transformed by electroporation separately into Agrobacterium tumefaciens strain GV3101 (pSoup). A mixture of equal parts of Agrobacterium suspensions of RNA1 and RNA2 was infiltrated into 2- to 3-week-old N. benthamiana leaves.

For cell death assay, Agrobacterium strain GV3101 (pSoup) carrying $N t M E K 2^{D D}$, INF1, $f f 9 / A v r 9$ or GUS (pGreen binary vectors) was infiltrated into the upper leaves of 4- to 5-week-old NbCAS-silenced N. benthamiana plants.

Microarray experiments and data analysis. The genome-wide microarray analyses were performed using the Arabidopsis v4 2 colour microarray (Agilent Technologies). Light grown, 2-week-old, wild-type and cas-1 mutant plants were floated on one-half MS medium for 1 day $(0 \mathrm{~h})$, and then treated with $1 \mu \mathrm{M} \mathrm{flg} 22$ for $2 \mathrm{~h}$. Total RNA was isolated with the Qiagen RNeasy plant mini kit following the manufacturer's instructions. Two independent biological replicates were performed for each sample and control. Each 200-ng total RNA sample was used to prepare Cy3- or Cy5-labelled target cRNA with the Low Input Quick Amp Labeling Kit (Agilent Technologies) and used in dual colour microarray hybridization with the Agilent Arabidopsis v4 oligo microarray slide. A dye-swap experiment was performed with two different RNA populations to eliminate the signal variation caused by the differential labelling efficiency of $\mathrm{Cy} 3$ and $\mathrm{Cy} 5$ dyes. The microarray data were normalized by the LOWESS method using the Feature Extraction software v. 10.7 (Agilent Technologies) and the expression ratios were analysed (Non-Uniformity Outlier and Feature Population Outlier). Data with a $P$-value of $>0.01$ were eliminated. The genes that showed a consistent expression pattern in cas- 1 and at least a twofold difference in the expression level in both slides are listed in Supplementary Data 1.

The genes induced by flg22 (ref. 17), by illumination of the $f l u$ mutant (chloroplast-derived ${ }^{1} \mathrm{O}_{2}{ }^{29}$ and the flu mutant overexpressing thylakoid-localized ascorbate peroxidase $\mathrm{e}^{29}$ and by $\mathrm{MV}^{30}$ were obtained from publications. To extract flu-regulated genes, raw signal intensity data (GSE10812) were obtained from the NCBI GEO database ${ }^{29}$. The genes that revealed a consistent expression pattern at $2 \mathrm{~h}$ after a dark-to-light shift in the flu mutant compared with wild type and exhibited at least a threefold difference in the expression level were used for this analysis.

Gene ontology and promoter sequence analyses. Gene ontology analysis was performed with the Arabidopsis Classification SuperViewer at the BAR of the University of Toronto. We compared the gene expression profiles of our microarray experiments with available expression data via the expression browser at BAR. We also searched for over-represented cis-elements in the 500-bp upstream regions of the down- and upregulated genes in flg22-treated cas-1 plants using the Regulatory Sequence Analysis tool (RSAT; http://rsat.ulb.ac.be/rsat).

\section{References}

1. Tsuda, K. \& Katagiri, F. Comparing signaling mechanisms engaged in patterntriggered and effector-triggered immunity. Curr. Opin. Plant Biol. 13, 459-465 (2010).

2. Grant, M. R. \& Jones, J. D. Hormone (dis)harmony moulds plant health and disease. Science 324, 750-752 (2009).

3. Padmanabhan, M. S. \& Dinesh-Kumar, S. P. All hands on deck-the role of chloroplasts, endoplasmic reticulum, and the nucleus in driving plant innate immunity. Mol. Plant Microbe Interact. 23, 1368-1380 (2010).

4. McAinsh, M. R. \& Pittman, J. K. Shaping the calcium signature. New Phytol. 181, 275-294 (2009).

5. Costa, A. et al. $\mathrm{H}_{2} \mathrm{O}_{2}$ in plant peroxisomes: an in vivo analysis uncovers a $\mathrm{Ca}^{2+}$-dependent scavenging system. Plant J. 62, 760-772 (2010).
6. Pinton, P., Giorgi, C., Siviero, R., Zecchini, E. \& Rizzuto, R. Calcium and apoptosis: ER-mitochondria $\mathrm{Ca}^{2+}$ transfer in the control of apoptosis. Oncogene 27, 6407-6418 (2008)

7. Han, S., Tang, R., Anderson, L. K., Woerner, T. E. \& Pei, Z.- M. A cell surface receptor mediates extracellular $\mathrm{Ca}^{2+}$ sensing in guard cells. Nature 425, 196-200 (2003).

8. Nomura, H., Komori, T., Kobori, M., Nakahira, Y. \& Shiina, T. Evidence for chloroplast control of external Ca${ }^{2+}$-induced cytosolic $\mathrm{Ca}^{2+}$ transients and stomatal closure. Plant J. 53, 988-998 (2008).

9. Weinl, S. et al. A plastid protein crucial for $\mathrm{Ca}^{2+}{ }^{2}$-regulated stomatal responses. New Phytol. 179, 675-686 (2008).

10. Vainonen, J. P. et al. Light regulation of CaS, a novel phosphoprotein in the thylakoid membrane of Arabidopsis thaliana. FEBS J. 275, 1767-1777 (2008).

11. Sai, J. \& Johnson, C. H. Dark-stimulated calcium ion fluxes in the chloroplast stroma and cytosol. Plant Cell 14, 1279-1291 (2002).

12. Petroutsos, D. et al. The chloroplast calcium sensor CAS is required for photoacclimation in Chlamydomonas reinhardtii. Plant Cell 23, 2950-2963 (2011).

13. Strawn, M. A. et al. Arabidopsis isochorismate synthase functional in pathogeninduced salicylate biosynthesis exhibits properties consistent with a role in diverse stress responses. J. Biol. Chem. 282, 5919-5933 (2007).

14. Tsuda, K., Sato, M., Glazebrook, J., Cohen, J. D. \& Katagiri, F. Interplay between MAMP-triggered and SA-mediated defense responses. Plant J. 53, 763-775 (2008).

15. Thilmony, R., Underwood, W. \& He, S. Y. Genome-wide transcriptional analysis of the Arabidopsis thaliana interaction with the plant pathogen Pseudomonas syringae pv. tomato DC3000 and the human pathogen Escherichia coli O157:H7. Plant J. 46, 34-53 (2006).

16. Zipfel, C. Pattern-recognition receptors in plant innate immunity. Curr. Opin. Immunol. 20, 10-16 (2008).

17. Denoux, C. et al. Activation of defense response pathways by OGs and Flg22 elicitors in Arabidopsis seedlings. Mol. Plant 1, 423-445 (2009).

18. Toufighi, K., Brady, S. M., Austin, R., Ly, E. \& Provart, N. J. The botany array resource: e-Northerns, expression angling, and promoter analyses. Plant J. 43, $153-163$ (2005)

19. Rushton, P. J., Somssich, I. E., Ringler, P. \& Shen, Q. J. WRKY transcription factors. Trend. Plant Sci. 15, 247-258 (2010).

20. Ishihama, N., Yamada, R., Yoshioka, M., Katou, S. \& Yoshioka, H. Phosphorylation of the Nicotiana benthamiana WRKY8 transcription factor by MAPK functions in the defense response. Plant Cell 23, 1153-1170 (2011).

21. van Verk, M. C., Bol, J. F. \& Linthorst, H. J. WRKY transcription factors involved in activation of SA biosynthesis genes. BMC Plant Biol. 11, 89 (2011).

22. Zhang, Y. et al. Control of salicylic acid synthesis and systemic acquired resistance by two members of a plant-specific family of transcription factors. Proc. Natl Acad. Sci. USA 107, 18220-18225 (2010).

23. Waters, M. T. et al. GLK transcription factors coordinate expression of the photosynthetic apparatus in Arabidopsis. Plant Cell 21, 1109-1128 (2009).

24. Sun, C.- W., Huang, Y.- C. \& Chang, H.- Y. CIA2 coordinately up-regulates protein import and synthesis in leaf chloroplasts. Plant Physiol. 150, 879-888 (2009).

25. Hudson, D. et al. GNC and CGA1 modulate chlorophyll biosynthesis and glutamate synthase (GLU1/Fd-GOGAT) expression in Arabidopsis. PLoS One 6, e26765 (2011).

26. Shiina, T., Tsunoyama, Y., Nakahira, Y. \& Khan, M. S. Plastid RNA polymerases promoters, and transcription regulators in higher plants. Int. Rev. Cytol. 244, 1-68 (2005).

27. Maclean, D., Jerome, C. A., Brown, A. P. C. \& Gray, J. C. Co-regulation of nuclear genes encoding plastid ribosomal proteins by light and plastid signals during seedling development in tobacco and Arabidopsis. Plant Mol. Biol. 66, 475-490 (2008).

28. Woodson, J. D. \& Chory, J. Coordination of gene expression between organellar and nuclear genomes. Nat. Rev. Genet. 9, 383-395 (2008).

29. Laloi, C. et al. Cross-talk between singlet oxygen- and hydrogen peroxidedependent signaling of stress responses in Arabidopsis thaliana. Proc. Natl. Acad. Sci. USA 104, 672-677 (2007)

30. Scarpeci, T. E., Zanor, M. I., Carrillo, N., Mueller-Roeber, B. \& Valle, E. M. Generation of superoxide anion in chloroplasts of Arabidopsis thaliana during active photosynthesis: a focus on rapidly induced genes. Plant Mol. Biol. 66, 361-378 (2008)

31. Bolton, M. D. Primary metabolism and plant defense-fuel for the fire. Mol. Plant Microbe Interact. 22, 487-497 (2009).

32. Tosti, N. et al. Gene expression profiles of $\mathrm{O}_{3}$-treated Arabidopsis plants. Plant Cell Environ. 29, 1686-1702 (2006).

33. Fernández, A. P. \& Strand, A. Retrograde signaling and plant stress: plastid signals initiate cellular stress responses. Curr. Opin. Plant Biol. 11, 509-513 (2008).

34. Zurbriggen, M. D. et al. Chloroplast-generated reactive oxygen species play a major role in localized cell death during the non-host interaction between tobacco and Xanthomonas campestris pv. vesicatoria. Plant J. 60, 962-973 (2009). 
35. Wang, W.- H. et al. Calcium-sensing receptor regulates stomatal closure through hydrogen peroxide and nitric oxide in response to extracellular calcium in Arabidopsis. J. Exp. Bot. 63, 177-190 (2012).

36. Lee, K. P., Kim, C., Landgraf, F. \& Apel, K. EXECUTER1- and EXECUTER2dependent transfer of stress-related signals from the plastid to the nucleus of Arabidopsis thaliana. Proc. Natl Acad. Sci. USA 104, 10270-10275 (2007).

37. Oschsenbein, C. et al. The role of EDS1 (enhanced disease susceptibility) during singlet oxygen-mediated stress responses of Arabidopsis. Plant J. 47, 445-456 (2006).

38. Xu, X., Hu, X., Neill, S. J., Fang, J. \& Cai, W. Fungal elicitor induces singlet oxygen generation, ethylene release and saponin synthesis in cultured cells of Panax ginseng C. A. Meyer. Plant Cell Physiol. 46, 947-954 (2005).

39. Saibo, N. J., Lourenço, T. \& Oliveira, M. M. Transcription factors and regulation of photosynthetic and related metabolism under environmental stresses. Ann. Bot. 103, 609-623 (2009)

40. Kallenbach, M., Alagna, F., Baldwin, I. T. \& Bonaventure, G. Nicotiana attenuata SIPK, WIPK, NPR1 and fatty acid-amino acid conjugates participate in the induction of JA biosynthesis by affecting early enzymatic steps in the pathway. Plant Physiol. 152, 96-106 (2010).

41. Tozawa, Y. et al. Calcium-activated (p)ppGpp synthetase in chloroplasts of land plants. J. Biol. Chem. 282, 35536-35545 (2007).

42. Kreimer, G., Melkonian, M., Holtum, J. A. M. \& Latzko, E. Stromal free calcium concentration and light-mediated activation of chloroplast fructose-1,6-bis phosphatase. Plant Physiol. 86, 423-428 (1998).

43. Caporaletti, D. et al. Non-reductive modulation of chloroplast fructose-1,6bisphosphatase by 2-Cys peroxiredoxin. Biochem. Biophys. Res. Commun. 355, 722-727 (2007).

44. Miqyass, M., van Gorkom, H. J. \& Yocum, C. F. The PSII calcium site revisited. Photosynth. Res. 93, 89-100 (2007).

45. Garmier, M. et al. Light and oxygen are not required for harpin-induced cell death. J. Biol. Chem. 282, 37556-37566 (2007).

46. Boccara, M. et al. Early chloroplastic alterations analysed by optical coherence tomography during a harpin-induced hypersensitive response. Plant J. 50, 338-346 (2007).

47. Triantaphylidès, C. \& Havaux, M. Singlet oxygen in plants: production, detoxification and signaling. Trends Plant Sci. 14, 219-228 (2009).

48. Jahns, P. \& Holzwarth, A. R. The role of the xanthophyll cycle and of lutein in photoprotection of photosystem II. Biochim. Biophys. Acta 1817, 182-193 (2012).

49. Roden, L. C. \& Ingle, R. A. Lights, rhythms, infection: the role of light and the circadian clock in determining the outcome of plant-pathogen interactions. Plant Cell 21, 2546-2552 (2009).

50. Wang, W. et al. Timing of plant immune responses by a central circadian regulator. Nature 470, 110-114 (2011).

51. Huner, N. P. A., Öquist, G. \& Sarhan, F. Energy balance and acclimation to light and cold. Trends Plant Sci. 3, 224-230 (1998).

52. Tang, R.- H. et al. Coupling diurnal cytosolic $\mathrm{Ca}^{2+}$ oscillations to the CAS-IP pathway in Arabidopsis. Science 315, 1423-1426 (2007).

53. Knight, H., Trewavas, A. J. \& Knight, M. R. Cold calcium signaling in Arabidopsis involves two cellular pools and a change in calcium signature after acclimation. Plant Cell 8, 489-503 (1996).
54. Rodoriguez-Kabana, R., Godoy, G., Morgan-Jones, G. \& Shelby, R. A. The determination of soil chitinase activity: conditions for assay and ecological studies. Plant Soil 75, 95-106 (1983).

55. Kim, M. G. et al. Two Pseudomonas syringae Type III effectors inhibit RIN4regulated basal defense in Arabidopsis. Cell 121, 749-759 (2005).

56. Izumi, Y., Okazawa, A., Bamba, T., Kobayashi, A. \& Fukusaki, E. Development of a method for comprehensive and quantitative analysis of plant hormones by highly sensitive nanoflow liquid chromatography-electrospray ionization-ion trap mass spectrometry. Anal. Chim. Acta 648, 215-225 (1999).

57. Sugimoto, T. et al. Use of ultra-performance liquid chromatography/timeof-flight mass spectrometry with nozzle-skimmer fragmentation for comprehensive quantitative analysis of secondary metabolites in Arabidopsis thaliana. J. Sep. Sci. 34, 3587-3596 (2011).

58. Ratcliff, F., Martin-Hernadez, A. M. \& Baulcombe, D. C. Tobacco rattle virus as a vector for analysis of gene function by silencing. Plant J. 25, 237-245 (2001)

\section{Acknowledgements}

We thank M. Isobe and M. Kuse for providing coelenterazine, D.C. Baulcombe for pTV00 vector, Y. Ohashi and I. Mitsuhara for the $N t M E K 2^{D D}$ clone, P. Mullineaux and R. Hellens for pGreen binary vector, S. Kamoun for INF1, J.D.G. Jones for $c f 9 / A v r 9$ and the Leaf Tobacco Research Center, Japan Tobacco, for N. benthamiana seeds. We also thank Y. Kubo, M.H. Sato, Y. Yagi and Y. Ishizaki for discussions, and T. Kimura and K. Yamasaki for technical assistance. This work was supported by Grants-in-Aid (No 20200060 to Y.N and 22370022 to T.S.), Private University Strategic Research Foundation Support Program (S0801060) and Joint Research Program implemented at the Institute of Plant Science and Resources, Okayama University from MEXT, and this work was also supported by the Program for Promotion of Basic Research Activities for Innovative Biosciences (PROBRAIN).

\section{Author contributions}

H.N., H.Y. and T. Shiina designed the research plan; H.N., T.K., S.U., Y.K., K.S., K.N T.F., S.S., I.N.S., H.Y., N.Y. and T. Shiina performed experiments; K.T., T. Sugimoto and E.F. carried out metabolome and hormone analyses; H.N. and T. Shiina wrote the manuscript.

\section{Additional information}

Accession codes: The NbCAS sequence has been deposited in the DNA Data Bank of Japan under accession code AB720027.

Supplementary Information accompanies this paper at http:/www.nature.com/ naturecommunications

Competing financial interests: The authors declare no competing financial interests.

Reprints and permission information is available online at http://npg.nature.com/ reprintsandpermissions/

How to cite this article: Nomura, H. et al. Chloroplast-mediated activation of plant immunity signalling in Arabidopsis. Nat. Commun. 3:926 doi: 10.1038/ncomms1926 (2012) 


\section{Corrigendum: Chloroplast-mediated activation of plant immune signalling in Arabidopsis}

Hironari Nomura, Teiko Komori, Shuhei Uemura, Yui Kanda, Koji Shimotani, Kana Nakai, Takuya Furuichi, Kohsuke Takebayashi, Takanori Sugimoto, Satoshi Sano, I Nengah Suwastika, Eiichiro Fukusaki, Hirofumi Yoshioka, Yoichi Nakahira \& Takashi Shiina

Nature Communications 3:926 doi: 10.1038/ncomms1926 (2012); Published 26 Jun 2012; Updated 5 Feb 2013

The affiliation details for Hirofumi Yoshioka and Yoichi Nakahira are incorrect in this Article. The correct affiliations for these authors are listed below.

Hirofumi Yoshioka ${ }^{2}$, Yoichi Nakahira ${ }^{1,5}$

${ }^{1}$ Graduate School of Life and Environmental Sciences, Kyoto Prefectural University, Sakyo-ku, Kyoto 606-8522, Japan. ${ }^{2}$ Graduate School of Bioagricultural Sciences, Nagoya University, Chikusa-ku, Nagoya 464-8601, Japan. ${ }^{5}$ The Venture Business Laboratory, Ehime University, Bunkyo-cho, Matsuyama 790-8577, Japan 